\title{
Update on epidemiology and control of Foot and Mouth Disease - A menace to international trade and global animal enterprise
}

\author{
P. M. Depa, Umesh Dimri, M.C. Sharma, Rupasi Tiwari \\ Indian Veterinary Research Institute, \\ I zatnagar-243122, Dist. Bareilly (UP) India \\ Corresponding author: P. M. Deepa, email: apdrdeepapm@gmail.com \\ Received: 02-04-2012, Accepted: 07-05-2012, Published Online: 15-09-2012 \\ doi: 10.5455/vetworld.2012.694-704
}

\begin{abstract}
Foot and mouth disease (FMD) is one of the most economically and socially devastating disease affecting animal agriculture throughout the world. This review describes economic impact of disease outbreaks, an update of recent findings in epidemiology of FMD both at International and national level and control of this disease. The etiological agent (FMD virus) is examined in detail at genetic and molecular characterization level and in terms of antigenic diversity.

Key words: carrier status, control, economic impact, molecular epidemiology, transmission,
\end{abstract}

To cite this article: Depa PM, Dimri U, Sharma MC, Tiwari R (2012) Update on epidemiology and control of Foot and Mouth Disease - A menace to international trade and global animal enterprise, Vet World, 5(11): 694-704, doi: 10.5455/vetworld.2012.694-704

\section{Introduction}

Livestock contributes significantly to the world economy. However, animal diseases are still a major constraint on economic growth, reduction of poverty and food security. Among the most significant disease is foot and mouth disease (FMD), a highly contagious, multi species animal disease with a devastating impact on national economics and trade. FMD affects worldwide and is included in the list of diseases notifiable to the World Organisation for Animal Health.

It is recognised as a significant epidemic threatening the cattle industry since sixteenth century and till date. It is a major global animal health problem. India is endemic for FMD and it is very much indispensable for our country to control this disease to increase productivity of livestock sector. In present article effort has been made to briefly review past, present concepts in epidemiology and control of FMD in International and National Scenario which may be of help in eradication of FMD.

\section{Economic impact}

FMD is the most contagious transboundary animal disease affecting cloven footed animals. Significant economic losses are produced by its high morbidity and the export trade restrictions imposed on affected countries. Many studies highlighted the severe impact on national economies with introduction of FMD could have in a FMD free country. FMD outbreak in UK in 2001 has negative consequence not only on agriculture and farming industry but also for the tourism sector resulting in a $0.2 \%$ reduction in GDP [1]. The total cost of that outbreak has been estimated at US \$ 9 to 13 billion, where there were at least US $\$ 4.5$ billion in direct costs US $\$ 9$ billion in agricultural and tourism sectors. Depopulation of $10 \%$ of state cattle herds in response to an FMD outbreak in USA generated total economic losses of US \$ 275 million and 9400 jobs [2]. There was severe outbreak of FMD during 2010-2011 in south Korea in which around 3 million cattle and pigs died and the economic loss due to this outbreak was estimated to be around 3 trillion won [USD 2.7 billion] [3]. In India, direct losses due to FMD are estimated to be more than 20,000 crores ( 4.45 billion USD) per year. Indirect losses due to FMD are about 30,000 to 35,000 crores annually [4]. FMD causes milk losses of approximately 3508 million litres per year, about $8.5 \%$ of total annual milk production [5]. A study conducted to evaluate the effect of FMD on milk yield at Andassa Government dairy farm, Ethiopia showed that the average milk yield 10 days ahead of FMD infection was found significantly higher than that of 10 days after the infection [6]. Economical loss due to FMD is tremendous that 
occurred due to death of young animals, marked reduction in milk yield, abortion in advanced pregnancy and reduced working ability of the animals [7], quality and quantity of meat, reduction in fertility, loss of quality of semen in breeding bulls [8], the disease also restricts the possible export of livestock and livestock products. The economic losses due to FMD were more to the marginal farmers and in animals less than three years of age [9]. This disease accounts for a milk loss of US $\$ 6.15$ per buffalo in India [5], and the production is affected up to $30 \%$ [10]. The median national loss ranged from $\$ 2.3$ billion to 69 billion as the diagnostic delay increased from 7-22 days. The median national loss was predicted to increase approximately $\$ 565$ million per hour of delay [11]. It is indicated that control of FMD could lead to at least $5 \%$ annual increase in milk production and present level of export of meat $(80,000$ tonnes) could be enhanced by 3-5 times [12]. It was estimated the losses by FMD, due to loss in draught power, animal death and cost of treatment of US\$ 446.11 million. The average annual loss per animal due to the FMD in the country was estimated US\$3.08 [5]. An approximate cost of US\$19.49, a farmer had incurred on treatment of FMD affected buffalo (the cost category include, immediate loss per buffalo, loss in milk production, cost of treatment i.e., antibiotics, vitamins, disinfectants and service of veterinary officer and cost of mortality) [13].

\section{Epidemiology}

FMD is the first disease on the OIE listed for which the OIE established an Official list of free countries and zones. At present, among 178 member states of World Organisation for Animal Health, 66 countries are FMD free (65 without vaccination, 1 with vaccination), 10 countries have FMD free zones. North America, Majority of South America, Western Europe, Australia, Newzealand and most Island countries in pacific are free of the disease. Countries like Botswana, Bulgaria, Chinese Taipei, South Africa, Kazakhstan, Libya, Paraguay, Russia and Namibia reported immediate outbreak notification to OIE. Morbidity rate ranged from 0.2 to $58.8 \%$ and mortality rate ranged from 0 to $14.51 \%$ [14].The morbidity rate by FMD is up to 100 per cent while mortality rate in adult is very low but in calves it is up to $20-25$ per cent [10]. A serological survey conducted between 2009 and 2011 in six Border States and two other states that lie on the major cattle trek routes in Nigeria showed a Higher seroprevalence in cattle samples from Yobe State $(82 \%)$, followed by those from Plateau (80\%), Ogun (77.77\%), Taraba (73.50\%), Adamawa (68\%), Borno (67\%), Sokoto (63\%) and Bauchi $(27.84 \%)$, is only in sheep and goat. None of the pig sera was positive. There is no difference in seropositivity between cattle sampled at the border and those from the trek routes. The result confirmed that FMD is still an important cattle disease in Nigeria [15]. FMD occurred recently for the first time in a decade in Japan on April 20, 2010. A total of 292 outbreaks had been confirmed with about 290,000 animals having been culled. Epidemiological investigations indicated that the disease was introduced into Japan approximately one month before detection. This delay in initial detection is considered to have allowed an increased number of outbreaks in the early stage of the epidemic [16].

The Regional Research Centre on FMD, Hisar, India has done a commendable work on epidemiology of FMD in north-west India. A total of 1718 FMD outbreaks were recorded by the Regional Centre, Hisar in the Haryana state since the inception of the project (1971-2010). Maximum number (169) of outbreaks recorded during 1976 coincided with heavy rains followed by widespread floods. Likewise, the lowest number of outbreaks recorded during 2004 to 2009 can be attributed to the implementation of FMDControl Programme in Haryana since January 2004.

In 2010-2011, 799 outbreaks were reported in different parts of India [17]. Maximum outbreaks were recorded in the eastern region where there was increase in the number of outbreaks compared to last year. Drastic reduction in outbreaks was noticed in southern region. FMD cases were not reported in Tamil Nadu, whereas Himachal Pradesh and Punjab recorded a single case of FMD each. Maximum incidence of disease was reported in March and from August to November [17] whereas maximum incidence of disease was recorded during December to March [18].

\section{Host species}

FMD affects all cloven footed animals. Cattle, sheep, goats, and pigs are the main domes-ticated species infected. The Water Buffalo (Bubalus bubalis) can become infected and may also transmit infection to other species. Current epidemic in China showed that O/Mya-98 strain mainly affected pigs, although cattle, goats and sheep affected in some field cases. However, PanAsia strain mainly affected cattle (19). The World Organization for Anima Heath (OIE) code chapter on FMD includes the camelidae as susceptible to FMD, similar to cattle, pigs, sheep and goat, but 
infection dynamics vary across a the species [20]. The two closely related camel species of Bactrian and dromedary camels posses noticeably different susceptibility to FMD virus [21]. Dromedary camels appeared to be susceptible with FMD serotype $\mathrm{O}$, but they are unlikely to play any significant role in the natural epidemiology of FMD [22]. A wide range of wild cloven-footed animals contract FMD including deer and wild pigs. African buffalos play an important role in the maintenance of FMDV infection within National Parks in Uganda. Both SAT 1 and SAT 2 viruses were isolated, and serological data indicate that it is also likely that FMDV serotypes $\mathrm{O}$ and SAT 3 may be present in the buffalo population [23].

Although FMD is known as a disease of clovenfooted animals it can occur naturally in other animals, e.g., the hedgehog (Erinaceus spp.) and infection has been established experimentally in a number of other species. However, it is doubtful whether these animals play any part in the epidemiology of the disease [24]. FMD is not considered zoonotic. Although clinical cases have been proven in human, these are extremely rare in relation to human exposure during outbreaks [24]. Epidemiological studies of FMD in North West India during 2003-04 showed that maximum number of outbreaks involved buffaloes and cattle (either simultaneously or alone) followed by goats and sheep (either simultaneously or alone). However during 2004-05 and 2005-06, cattle and buffaloes were involved only simultaneously. It is worthwhile to mention that during 2006-07 and 2007-08 no other species except cattle were involved in FMD outbreaks. Further during subsequent years the number of outbreaks remained confined to 1-2 only [25].

In the recent outbreaks during 2011 in different countries the majority of species affected are cattle, swine and sheep. Source of recent outbreak due to wild life species has been reported in South Africa and Namibia [14]. Larger outbreaks occurred in winter within the higher deer-density eco region, whereas larger outbreaks occurred in summer and fall within the lower deer-density eco region. Results of this simulation study suggest that the outcome of an FMD incursion in a population of wildlife would depend on the density of the population infected and when during the year the incursion occurs [26]. In recent outbreaks in India, the majority of species involved was cattle, although disease reported in buffaloes, pigs, sheep and goats [17]

\section{Molecular Epidemiology and Genetic chara- cterization}

There are seven recognised serotypes of FMD
(O, A, C, Asia 1, SAT 1, SAT 2, SAT 3), which differ in distribution across the world. Serotype $A$ and $O$ have the widest distribution, occurring in Africa, Asia and South America. However, Asia has its own unique serotype, Asia 1, first detected in samples collected in India in 1951 through 1952 [27] and Pakistan in 1954 [28]. The primary serotype-endemic region for Asia 1 seems to be the Indian subcontinent (Afghanistan, India, Pakistan, Bhutan, and Nepal).

This serotype has been more sporadically reported from countries to the west or east; it has spread periodically into the Middle East and occasionally to Europe [29], but it has not been reported from Africa or the America. Since 2004, the region affected by outbreaks of Asia 1 serotype has increased from disease-endemic countries in southern Asia. Phylogenetic analysis of complete virus capsid protein 1 (VP1) gene sequences demonstrated that the FMDV isolates responsible for these outbreaks belonged to 6 groups within the Asia 1 serotype. Some contemporary strains were genetically closely related to isolates collected historically from the region as far back as 25 years ago indicating that some viruses have spread large distances between countries in Asia within a short time [30]. A study that reviewed FMDV in the West Bengal region of India described recovery of Asia 1 from only $15 \%$ of FMD cases examined between 1985 and 2002 [31].

Similarly, in Southeast Asia, where serotypes O and $A$ are prevalent every year, outbreaks due to Asia 1 have been reported only sporadically in the past 10 years; a recent gap in reporting occurred between 2002 and 2005. Types SAT1, 2 and 3 are currently restricted to Africa only and Asia 1 to Asia, but the capacity to invade other areas is common to all types and periodically SATs are introduced into the Near East and Asia 1 into Western and eastern parts of Eurasia [32]. During 2004, evidence showed possible northward spread of the Asia 1 serotype; outbreaks were reported in Kyrgyzstan and Tajikistan. In early 2005, an outbreak was recorded in Hong Kong Special Administrative Region, People's Republic of China, which suggested that the virus might have crossed China. Later in 2005 and 2006, outbreaks of FMD Asia 1 were reported in several provinces and autonomous regions of China and in Mongolia and Eastern Russia [32]. In 2005 and 2006, this serotype reappeared in Southeast Asia (Vietnam and Myanmar). In the year 2005-2006, three incursions of FMD were reported in countries or zones declared officially free by the OIE in Argentina (type O in February 2006), Brazil (type O in September and October 2005) and Botswana (Type SAT 2 in April 2006). In mid-2005, a rapid escalation 
of type A outbreaks occurred in Iran for which the routine vaccination provided little effective immunity. The virus strain involved named A Iran 05 by the FAO World Reference Laboratory has isolated from outbreaks in Saudi Arabia, Pakistan, and Jordan in 2006 indicates a wider distribution and capacity of the strain for further spread [32]. Viruses of serotype C now appear extremely rare. The last confirmed case was in Kenya in 2005 and the Amazon region of Brazil in 2004 [32].

In the current year, serotype $\mathrm{O}$ was most prevalent in majority of the outbreaks recorded in different countries [32]. In African countries serotype SAT2 was mainly responsible for outbreaks [33]. First occurrence of 'O ion South East Asia (SEA) topotype' was reported in the outbreak of FMD in swine in Chinese Taipei [14]. Three serotypes currently prevalent in India are $\mathrm{O}, \mathrm{A}$ and Asia1. Serotype $\mathrm{O}$ is responsible for 70 to $80 \%$ of outbreaks followed by A and Asia1 [17]. The serotype $\mathrm{C}$ was last recorded in 1995 [17]. Antigenic analysis of sixteen field isolates of FMD virus serotype $\mathrm{O}$ in the current year showed that all isolates were antigenically related to currently used vaccine strain (O/IND/ R2/1975). Major shift in genetic lineage of serotype $\mathrm{O}$ virus was observed circulating in India. Viruses of 'Ind 2001 lineage' gained upper hand after a gap of 8 years and outcompeted pan Asia II lineage in early part of 2008 [17]. The re-emergence of 'Ind 2001 lineage' has been traced back to 2008, during which it caused sporadic outbreaks in Northern India [17].

Among seven serotypes of FMD, type A virus has been genetically and antigenically most heterogeneous in nature. Global genotyping revealed 26 regional genotypes within three continental topotypes. Continental topotypes are Asian, Europe- South American and African. During the last decade, ten genotypes have been in circulation the world over and it was evident that no type A strain has transgressed the continental barriers during this period [34].

VP 1 coding region based molecular phylogeny has established circulation of 4 genotypes so far in India. Since 2001, Genotype 18 (VII) has been exclusively responsible for all field outbreaks and has outcompeted all other genotypes. Within the currently circulating genotype 18 (VII) a divergent and unique lineage emerged in late part of 2002, which showed an amino acid deletion at $59^{\text {th }}$ position of VP3 and dominated the field outbreak scenario in 2002-03 [35]. This deletion is at antigenically critical position in structural protein VP3, which is considered to be a major evolutionary jump probably due to immune selection in sparsely vaccinated population of cattle and buffalo [36]. In 2010-2011, co circulation of both $\mathrm{VP}^{53}$ deletion and non deletion mutants were reported. $80 \%$ of field strains showed close antigenic match with vaccine strain (IND 40/2000) which offers optimum antigenic coverage over field strains. However IND45/2010 from UP and IND 136/2010 from Haryana showed poor antigenic relation with current vaccine strain [19].

Three different groups of FMDV serotype Asia 1 have been circulating in Pakistan and Afghanistan since 1998. Serotype Asia 1 was detected again in 2008-2009 after a gap of 4 years in Afghanistan and 2 years in Pakistan. A variant of group VII Asia 1 viruses has arisen as a result of recombination between viruses belonging to group VII of serotype Asia 1 and serotype A virus of A- Iran 05 sub lineage presumably due to simultaneous infection of animals with these two viruses. Asia1 / Shamir strain which is being used in the current FMD vaccine may not efficiently protect against Asia1 viruses circulating in Pakistan and Afghanistan in 2008-09 [37]. Molecular phylogeny based on VP1Coding region showed 3 prominent lineages in India. Lineage B included in vaccine strain (IND 63/72) did not appear after 2000. Lineage $C$ was prominently circulating during the period 1993 to 2001[38]. A novel divergent genetic lineage (lineage D) within lineage C appeared in 2001 and outnumbered in parent 1 lineage in terms of field outbreaks. Lineage $\mathrm{C}$ has been responsible for all Asia 1 outbreaks in the country since 2005 . Outbreaks due to Asia1 isolates are constantly reported from Gujarat [19].

The type $\mathrm{C}$ virus is the least prevalent of all the serotypes, causing about $8 \%$ of all FMD outbreaks during 1977 to 1990 and $1.6 \%$ during 1991 to 1994 . Since 1996, type C outbreaks have not been recorded in India, and the World Reference Laboratory for FMD (Pirbright, United Kingdom) has not received any isolates during the past 8 years. The $1 \mathrm{D}$ region in the viral RNA codes for a major antigenic site consisting of the GH loop (140 to 160 amino acids) and a minor antigenic site (205 to 210 amino acids) at the C terminus of VP1 protein. These two sites are considered important for phylogenetic analysis, because genetic and antigenic variations in these sites are ascribed to differences among strains [39]. Until recently two vaccine strains, C Bombay/64 and C IND/51/79, have been used in India; either of these strains was included in quadrivalent vaccines by different vaccine manufacturers. The phylogenetic analysis revealed seven distinct genotypes for the type $\mathrm{C}$ viruses. The 
Southeast Asian and Indian isolates are grouped under two distinct genotypes-genotypes VI and VII, respectively. In the phylogenetic tree the $\mathrm{C}$ Bombay/64 strain is grouped with the European strains (genotype III). The C IND/51/79 is grouped with the Indian isolates but as a distinct lineage (genotype VII). The type $\mathrm{C}$ viruses in the subcontinent are not clearly descendants of the vaccine strains. The Indian type $C$ viruses have a distinct evolution pattern and require further scrutiny to determine the origin of the type $\mathrm{C}$ viruses in India. The vaccine strain $\mathrm{C}$ IND/51/79 has a wide antigenic spectrum, and is genetically related to the type $\mathrm{C}$ Indian isolates. This strain was characterized at the World Reference Laboratory, Pirbright, United Kingdom, after it was isolated from an outbreak in the state of Tamil Nadu, India. This vaccine strain was a part of the quadrivalent vaccine manufactured by Indian Immunologicals Ltd., Hyderabad, India, with technical support from the Wellcome Research Foundation, London, United Kingdom. Because of its homology to the Indian isolates, the $\mathrm{C}$ IND/51/79 may be considered a prototype strain of the type $\mathrm{C}$ viruses of Indian origin. Although type $\mathrm{C}$ outbreaks have been minimal, study shows that future type C FMD outbreaks in India and South Asia could be controlled by the use of C IND/51/79 vaccine strain [39].

Type $\mathrm{O}$ virus was found to be the dominant FMD virus type during 1971 to 2010 in North West India except in 1976 and 1984 when Asial overtook other virus types. FMD virus subtype A22 was recovered from vaccinated organized farms. The vaccine earlier did not contain this virus type. Based on the recommendations of this centre, a polyvalent FMD vaccine containing A22 virus subtype is now commercially available. The incorporation of FMD virus subtype A22 in vaccine resulted in drastic reduction of FMD outbreaks due to this subtype.FMD virus type $\mathrm{C}$ has not been recorded in this region since 1991. Based on this information, Govt. of India has recommended the use of trivalent FMD vaccine (containing FMD virus types O, A22 and Asia1) instead of quadrivalent vaccine (used previously) in the recently launched FMD-Control Programme. This has led to drastic reduction in the cost of FMD vaccine resulting in savings of crores of rupees in government exchequer [25].

\section{Transmission}

Cattle are very susceptible by respiratory route requiring as little as 20 TCID $_{50}$ of virus to establish infection but require 10,000 times more to become infected by oral route.

While pigs are relatively resistant to infection by airborne FMD virus. Minimum dose of airborne virus required to infect pigs is more than $800 \mathrm{TCID}_{50}$. Wind borne aerosol virus produced by infected animals are carried over $250 \mathrm{kms}$ [40]. Survival of virus in aerosols depends on relative humidity [41]. Cattle are mainly infected by inhalation, often from pigs, which excrete large amount of virus by respiratory aerosols and are considered highly important in disease spread. Large amounts of virus are excreted by infected animals before clinical signs are evident and wind may spread the virus over long distances [42]. Milk and semen from infected cattle may contain virus up to 4 days before onset of observable signs, but peaks at $\log _{10} 6.7$ $\mathrm{TCID}_{50} / \mathrm{ml}$ of milk and $\log _{10} 6.2 \mathrm{TCID}_{50} / \mathrm{ml}$ of semen as vesicles first appear. Urine may contain $\log _{10} 4.9$ $\mathrm{TCID}_{50 /} \mathrm{ml}$ and faeces $\log _{10} 5 \mathrm{TCID}_{50} / \mathrm{gm}$ [43]. A novel direct contact transmission model for the study of footand-mouth disease virus (FMDV) infection of swine was utilized to investigate transmission characteristics of three FMDV strains belonging to serotypes A, O and Asia1. Each strain demonstrated distinct transmission characteristics and required different exposure times to achieve successful contact transmission. While a $4 \mathrm{~h}$ exposure was sufficient for strain A24 Cruzeiro (A24Cru), both O1 Manisa and Asia1 Shamir transmission required $18 \mathrm{~h}$ or more. Viral excretion levels from donors (for all three strains) and virus present in room air (for A24Cru and O1 Manisa) were evaluated and associated with clinical signs and observed transmission pattern. Virus levels in room air were higher and were detected longer for A24Cru than for O1 Manisa. These results indicated that direct evidence for important strain-specific variation in transmission characteristics and emphasized the need for thorough evaluation of different FMDV viral strains using a well defined contact transmission methodology. This information is critical for vaccine and bio therapeutic efficacy testing, pathogenesis and disease modelling of FMDV transmission. [44].

\section{The Carrier State}

Frequency of FMD virus (FMDV) carrier state in cattle in Iran which is endemic to FMD showed $37.7 \%$ of cattle were carriers of the virus. Among positive samples, $60.4 \%$ belonged to serotype $\mathrm{O}$. No evidence was detected for the presence of Asia 1 and A serotypes. Timely estimation of the frequency of carrier state both in cattle and small ruminants is advocated as a gauge to monitor the virus status in the region [45]. A carrier is defined as one from which 
virus can be recovered 28 days or more after infection. The infectivity and pathogenicity of FMDV persistent infection in cattle in China demonstrated that the virulence of the persistent infection strain $\mathrm{O} / \mathrm{CHN} /$ 2010/33-OP was lower than popular strain O/CHN/ Mya 98/2010. The persistent infection has infectivity and pathogenicity to cattle and pigs, so it is very important to detect FMD persistent infected animals and eliminate carriers to control the outbreaks [46]. The carrier period appears to vary between species, being in excess of 12 months in cattle, up to 9 months in sheep and goats and at least 5 years in African Buffalo [24]. A replication analysis of foot and mouth disease virus in swine to study carrier stage showed that "pseudopersistent state" may occur in pigs in which virus replicates in lymphoid tissues for a prolonged period of time, thereby representing a potential source of virus [47].

One study conducted to assess carrier status, persistence of virus following vaccination and challenge in sheep and goat suggested that vaccination offers protection from clinical disease even at a low payload of $0.94 \mu \mathrm{g}$ and hence one-half of cattle dose of the oil-based vaccine formulations is sufficient to induce protective immune response in sheep and goats. Since no live virus could be isolated after 5 days post challenge from the nasal swab or probang samples even though viral RNA was detected, the risk of these animals transmitting disease was probably very low [48]. FMDV locates rapidly to, and is maintained in, the light zone of germinal centres following primary infection of naïve cattle. Maintenance of non-replicating FMDV in these sites represents a source of persisting infectious virus and also contributes to the generation of long-lasting antibody responses against neutralising epitopes of the virus [49]. Stress of moving and mixing carrier cattle was sufficient to cause these animals to start excreting virus to precipitate a new outbreak [50].

\section{Control of FMD}

Countries in different regions of world adopt FMD control policies depending on the epidemiology of disease. In FMD free countries, slaughter of all infected and susceptible in contact animals, quarantine of infected animals, strict animal and animal product import regulation and animal movement restrictions are practiced. FMD endemic countries do not follow stamping out policy and use only vaccination as a measure of control. For effective control of FMD about $60-80 \%$ of animals need to be covered under vaccination so as to control the outbreak of diseases
[13]. It can be made possible only through implementation of veterinary extension education for livestock owners about economics of the diseases and by readily availability of vaccination service. There was no FMD outbreak in organized farm due to regular and proper vaccination [51]. Pertaining to the benefits derived by the livestock owners by vaccination of their buffaloes against FMD, 37.15 per cent of the owners reported that they save US\$9.87-14.76/ animals/lactation, whereas 25.53 per cent and 20.08 per cent of the buffalo owners were saving US\$14.79-19.61 and US\$ 4.95- 9.84/animal/lactation, if they vaccinate their animals against FMD. The awareness created about FMD vaccination among the buffalo owners made them regularly vaccinating their animals which has resulted into negligible cases of FMD in linkage villages [13]. The use of a zoning approach with vaccination in the endemic area of the Sagaing Division of Myanmar was found to be an appropriate option for the control of FMD. The complex animal movement patterns and the endemic nature of the disease pose real challenges for its control. However, in Myanmar the MTD meeting approach is a costeffective option for surveillance to improve the FMD status early in an eradication campaign [52].

\section{Outbreak management}

Outbreaks can be controlled by one or a combination of two methods: Stamping out (slaughter of all infected and in contact animals) and routine vaccination of animals [53]. In areas densely populated with livestock and in particular with regards to pigs, ring vaccination poses a valuable tool to deal economically with an outbreak that is recognised early. Ring vaccination possibly within the infected premises can be employed to control the spread of disease [54]. In areas sparsely populated with livestock, stamping out or ring culling is optimal method for dealing with an outbreak [55]. As a part of Animal Disease Control Project for FMD control in Kerala, outbreaks were controlled by restricting animal movement from and to the foci of infection; thorough disinfection of infected premises and treatment of ailing animals, and conducting ring Vaccinations, extending from the periphery to the point of infection within a radius of 5-10 Kms [56].

\section{Disinfection}

Common house hold bleach is effective disinfectant of FMD virus at concentration of $3 \%$. It can be used as on infected premises, but not a good choice for disinfection of equipments and foot paths. Vinegar at $4-5 \%$ dilution also kills the virus. Lye can be used at 
$2 \%$ dilution, but this is highly caustic. New disinfectants like Virkos S (per oxygen molecule/ organic acid/ surfactant combination) appear to have wider spectrum of activity against many germs including FMD virus. Another compound based on per oxy acetic acid (oxy-sept333), now Environmental Protection Agency (EPA) approved for FMD virus [57].

\section{Vaccination}

Argentina suffered an extensive foot-and-mouth disease (FMD) epidemic between July 2000 and January 2002, 3 months after obtaining the official FMD-free without vaccination status conferred by the World Organization for Animal Health. This is one of the largest FMD epidemics controlled by implementation of a systematic mass vaccination campaign in an FMD-free country. The result of the study demonstrates the protective impact of vaccination in reducing FMD transmission in infected herds [58]. Vaccines are widely employed to control FMD. As early as 1920, FMD losses in Europe were controlled by quarantining the infected animals and often deliberately spreading disease which involved rubbing the tongue of healthy cattle with a rough towel contaminated with virus from naturally infected cattle. This was referred to as Aphthisation. In 1925, first report of successful immunization of calves with formalized emulsion of vesicular epithelium was published. The first FMD vaccine was produced in 1938 using tongue epithelium harvested from cattle deliberately infected with FMD virus [59]. The oil adjuvant vaccine elicited superior immune response at any given period of study than aluminium hydroxide gel vaccine and immunity maintained for longer period. These observations suggest that the oil adjuvenated vaccine has potential to replace the commercial aluminium hydroxide gel vaccine [60].

However, these vaccines continue to be produced around the world for use mostly in ruminants. Oil adjuvant single and double emulsions are used to produce vaccine for immunisation of all species of animals including pigs. Oil adjuvant vaccine should have potency of at least $3 \mathrm{PD}_{50}$ and provide protective immunity within 7 days in cattle, swine and sheep [61]. Revaccination must be carried out every 6 months [62]. After multiple doses of vaccines in older animals vaccination frequency could be decreased to once a year provided that no new strains not covered by the vaccine formulation emerge or are introduced (63). There are important shortcomings of current inactivated vaccines, including short shelf life, the need for adequate cold chain of formulated vaccines, and difficulties of certain serotypes and subtypes to grow well in cell culture for vaccine production [64]. Subunit vaccine is a vaccine containing viral antigens made free of viral nucleic acid by chemical extraction or bio-expressing and containing only minimal amounts of non-viral antigens derived from the culture medium. It is less likely to cause adverse reactions than a vaccine containing the whole virion. But novel vaccines against FMDV are developed slowly, and only few available novel FMD vaccines have been used in practice. A number of results implied that there were observed advantages and disadvantages on novel vaccines arrange the security of production, the security of vaccinated animal, shelf life, duration of immune response, vaccination effectiveness and differentiation of infected animals from vaccinated ones [65].

Vaccination using plasmid DNA containing FMDV sequences has been reported as an efficient way to induce protective immunity in the mouse model [66]. Protection by DNA vaccination in farm animals has proven challenging and requires multiple doses and addition of adjuvant and cytokines to induce only partial or in some cases full protection [67]. Despite short comings, DNA vaccines are appealing because plasmid DNA does not require high containment facilities for manufacture, is relatively stable for storage, allows for rapid incorporation of emerging field strain sequence and allows discrimination between infected and vaccinated animals [66]. Delivery of plasmid coated on cationic PLG micro particles enhance the duration of immunity of the DNA vaccine constructs [68]. In a study it was found that all DNA vaccinated cattle developed good humoral and cell mediated responses prior to challenge. The best overall virus neutralising antibody, IFN- $\gamma$ and clinical protection $(75 \%)$ were seen in the cattle whereby the DNA was delivered by electroporation. In contrast, only $25 \%$ of cattle vaccinated with the DNAvaccine without electroporation were clinically protected. The addition of GM-CSF in combination with electroporation further improved the efficacy of the vaccine, as demonstrated from the reduction of clinical disease and virus excretions in nasal swabs. Thus demonstrated for the first time that cattle can be clinically protected against FMDV challenge following a DNA prime-protein boost strategy, and particularly when DNAvaccine is combined with GM-CSF and delivered by electroporation [69].

FMDV peptide vaccine adjuvanted with cholera toxin and administered intramuscularly elicited antipeptide antibodies with enhanced virus neutralizing 
activity in mice [70]. The recent development of dendrimeric peptides are copy of an FMDV $\mathrm{T}$ cell epitope branching out into 4 copies of a B cell epitope provides potential improvements over the conventional linear peptide [71].

The human replication-defective adenovirus vectored FMD (hAd5-FMD) vaccines are shown to be as effective as inactivated vaccine. Complete protection has been shown both in swine and cattle receiving one vaccine dose and challenged as early as 7dpv [72]. These new molecular FMD vaccine candidates are currently being manufactured in experimental batches and tested in cattle in US as a part of Veterinary licensing process [73]. Project Directorate on FMD along with United State Department of AgricultureAgriculture Research Service (USDA-ARS) finalised a collaborative programme for development of viral vectored molecular vaccine against FMD.

Regional Research Centre on FMD, Hisar, india has done a work on immunological interventions in naturally infected/ vaccinated buffalo calves. The studies conducted on immunogenicity of FMD virus revealed the involvement of cellular immune response as revealed by an increase in T-lymphocyte population. FMD infected/vaccinated animals showed higher proportions of circulating gamma/delta T-cell population. This was the first report implicating cellular immune response in FMD infected/vaccinated buffaloes [25].

\section{Conclusion}

Foot and mouth disease (FMD) is one of the highly contagious diseases of domestic animals. Economics of FMD control cannot be estimated without sound basis of FMD epidemiology. Molecular epidemiological studies help in planning control strategies by elucidating current disease transmission patterns within and between countries. One of the main limitations to FMD eradication is lack of effective vaccines designed for this purpose, vaccines that not only protect against clinical signs but that can actually prevent infection. High levels of genetic diversity will most likely be reflected in antigenic differences and it has been shown that for vaccination to be effective, the viruses incorporated in to the vaccines need to be antigenically related to viruses circulating in the field. Furthermore, there is a need for better integrated strategies that fit specific needs of endemic regions. Availability of these critical components will greatly enhance the chances for global control and eradication of FMDV.

\section{References}

1. Thompson, D., Muriel, P.,Russell, D., Osborne, P.,
Bromley, A., Rowland, M., Creigh-Tyte, S., and Brown, C.(2002). Economic costs of the foot and mouth disease outbreak in the United Kingdom in 2001. In Foot and mouth disease: facing the new dilemmas. Rev.sci.tech. Off. Int. Epiz. 21(3): 675-687.

2. Garner, M.G., Fisher, B.S., \& Murray, J.G. (2002). Economic aspects of foot and mouth disease: Prospective of a free country, Australia. In foot and mouth disease: facing new dilemmas. Rev. Sci. Tech. Off. Int. Epiz, 21 (3): 625-635.

3. http://www.koreatimes.co.kr/www/news/opinon/ 2011/10/137 97523.html dated 28/8/2011.

4. ICAR report in The Econmic times, August 23, 2011.

5. Saxena, R. (1994). Economic value of milk loss caused by foot and mouth disease (FMD) in India. Institute of Rural Management (RM) working paper No.60. IRM, Anand, 1-20.Annual Report, (20102011). Project Directorate on FMD. Mukteswar, Nainital, India.

6. Mazengia,H, Taye, M, Negussie, H, Alemu, S and Tassew, A (2010). Incidence of foot and mouth disease and its effect on milk yield in dairy catte at Andassa Dairy farm, North West, Ethiopia.Agriculture and Biology Journal of North America. ISSN online 21517525. doi:10.5251/abjna.2010.1.5.969.973

7. Jensen, K., English, B.C., \& Menard, J.(2003). Projected economic impacts of a foot and mouth disease (FMD) outbreak in Tennessee. Agri-industry Modelling and 201Analysis Group Industry briefAvailable at: http://web.utk.edu/ aimag/.pubs/ FMD.Pdf

8. Tung, D.X., \& Thuy, N.T. (2007). Economic impact assessment of foot and mouth disease on small holder farms in Northern Vietnam: control of transboundary animal diseases in the greater Mekong sub region project. Asian Development Bank. FAO, Rome.1-39.

9. Rufaul. T, Catley. A, Boge.A, Sahle. M and Shiferaw. Y.(2008). Foot and mouth disease in the Borana pastoral system, Southern Ethiopia and implications for livelihoods and internationaltrade. Trop. Anim. Heath. Prood. 40(1): 29-38.

10. Sharma, M. C and Mahesh, K (2003). Infectious Diseases of Buffalo. In: Proceedings of the $4^{\text {th }}$ Asian Buffalo Congress on "Buffalo for Food Security and Rural employment", held at New Delhi, during February 25-28, 2003. Volume 1:152-168.

11. Carpenter, T.E, Joshua, M., O'Brien, Hagerman, A.D and Mc Carl, B.A (2011). Epidemic and Economic impacts of delayed detection of FMD disease: a case study of a simulated outbreak in California. J.Vet. Diagn. Invest 23: 26-33.

12. Bhat, P. N and Taneja, V. K(2001). Foot and Mouth Diseases- Is it an International Convern now. Indian Dairyman. 53 (5):5.

13. Singh.B.P, Sharma, M.C, and Tiwari.R(2007). Foot and mouth disease vaccination in linkage villages of IVRI's India. Livestock Research for rural development 19(8). 
14. www.oie.int

15. Lazarus, D. D., Schielen, Wungak, W. J. G., Kwange, D. Y.and Fasina, F. O.(2012). Sero-epidemiology of foot-and-mouth disease in some Border States of Nigeria. African Journal of Microbiology Research Vol. 6(8),pp. 1756-1761

16. Muroga,N., Hayama,Y., Yamamoto,T., Kurogi,A., Tsuda, T And Tsutsui,T. (2011). The Foot and Mouth disease epidemic in Japan. J.Vet.Med.Sci. Nov 11.

17. Annual Report (2010-2011). Project Directorate on FMD, Mukteswar, Nainital, Uttarachal.

18. Annual Report, (2010-2011). Indian Council of Agricultural Research, New Delhi, India.

19. www.reuters.com/article/.../idUS20699+01-Feb2011+BW20110201 dated 31.1.2011.

20. World Organisation for Animal Health (OIE) (2009). Foot and mouth disease. OIE Terrestrial Mannual,2009. Chapter2.1.5.http:www.oie.int/ eng/A_FMD2012/docs/2.01.05_FMD.pdf.

21. Larskar.M, Wernery. U, Kinne. J, Schuskr. R, Aexandersen.G and Aexandersen, S (2009). Differences in the susceptibility of dromedary and Bactrian camels to foot and mouth disease virus. Epidemo. Infect., 137:549-554.

22. Yousef.M.R, Mazoum.K.S, A-Nakhali. H.M. (2012). Serological evidence of natural exposure of camels (camelus dromedaries) to foot and mouth disease virus. Vet. World. 5(4):197-200.

23. Ayebazibwe.C, Mwiine.F.N, Tjornehoj.K, Bainda.S.N, Muwanika.V.B,Okurut. A.R.A, Besham.G.J, Normann.P, Seigismund.H.R and Aexandersen. S (2010). The role of African Buffaloes (Syncerus caffer) in the maintenance of foot and mouth disease in Uganda. BMC Veterinary Research. 6:54.

24. Davies. G.(2002). Foot and mouth disease. Research in Veterinary Science. 73:195-199.

25. Report of Regional Research Centre on FMD, LLRUVAS, Hisar. llruvas.edu.in/rrc-fmd.php?AM2

26. Highfield,L.D., Ward,M.P., Laffan,S.W. , Bo Norby, and Wagner,G.(2009). The impact of seasonal variability in wildlife populations on the predicted spread of foot and mouth disease. Vet Res. 40(3): 18.

27. Dhanda, M.R, Gopalakrishnan, V.R, Dhillon, H.S. (1957). Note on the occurrence of atypical strains of foot-and-mouth diseases virus in India. Indian Journal of Veterinary Science. 27:79-84.

28. Brooksby, J.B, Rogers, J. (1957). Methods used in typing the virus of foot-and-mouth disease at Pirbright, 1950-55. In: Methods of typing and cultivation of foot-and-mouth disease virus. Paris: European Productivity Agency of the Organization for European Economic Co-operation. 31-34.

29. Schumann, K.R, Knowles, N.J, Davies, P.R, Midgley, R.J, Valarcher, J.F and Raoufi, A.Q (2008). Genetic characterization and molecular epidemiology of footand-mouth disease viruses isolated from Afghanistan in 2003-2005. Virus Genes. 36:401-413.
30. Valarcher,J.F, Knowles, N.J, Zakharov, V, Scherbakov, A, Zhang,Z, Shang,Y.J, Liu, Z.X, Liu,X.T, Sanyal,A, Hemadri, D, Rasool C.T.T.J, Pattnaik,B, Schumann,K.R,. Beckham,T.R, Linchongsubongkoch, W, Ferris,N.P, Roeder, P.L and Pa, D.J.(2009). Multiple Origins of Foot-andMouth Disease Virus Serotype Asia 1 Outbreaks, 2003-2007.Emerging Infectious Diseases.15 (7). wwwnc.cdc.gov/eid/article/15/7/08-1621.htmUnited States.

31. Bhattacharya, S., Banerjee, R., Ghosh, R., Chattopadhayay, A.P., Chatterjee, A. (2005). Studies of the outbreaks of foot and mouth disease in West Bengal. India, between 1985 and 2002. Revue Scientifique et Technique de l'Office International des Epizooties. 24:945-52.

32. www.fao.org/docs/eims/upload//225050/Focus_ ON_1_07_en.pdf ,Empress, 2007

33. www.fao.org/ag/againfo/commissions/docs/ research.../App18.pdf.

34. Mohapatra, J.K., Pandey, L.K., Sharma, G.K., Barik, S.K., Pawar, S.S.,Palasamy, R. \& Pattnaik, B. (2011). Multiplex PCR for rapid detection of serotype A foot and mouth disease virus variants with aminoacid deletion at position 59 of the capsid protein VP3. Journal of virological methods, 171: 289-291.

35. Rudreshappa, A.G, Sanyal,A, Mohapatra,K.J, Subramaniam,S, De, A, Das, B,Nagendrakumar ,B. Singanallur, Jangam,K.A, Muthukrishnan,M Villuppanoor, S Pattnaik,B(2012). Emergence of antigenic variants with in serotype $A$ foot and mouth disease virus in India and evaluation of a new vaccine candidate panel.Veterinary Microbiology. www.sciencedirect.com/science/ article/pii/S0378113512001459.

36. Jangra,R.K., Chakradhar, T., Sanyal,A., Hemadri,A., Bandyopadhyay, S.K. (2005). Antigenic and genetic analyses of foot and mouth disease virus type A isolates for selection of candidate vaccine strain reveals emergence of a variant virus that is responsible for most recent outbreaks in India .Virus Research, 112:52-59.

37. Jamal, S .M., Ferrari,G., Ahmed,S., Normann, P., Belsham,G.J.(2011). Molecular characterization of serotype Asia 1 foot and mouth disease viruses in Pakistan and Afghanistan: Emergence of a new genetic group and evidence for a novel recombinant virus. Infection, genetics and Evolution.xxx:14.

38. Rana, S.K. \& Bagch, T. (2008). Partial sequence analysis of VP1 of Indian isolates of FMD virus type Asia1, Virus Genes, 37(1):60-68.

39. Nagendrakumar,S.B., Reddy,G.S., Chandran,D., Thiagarajan,D., Rangarajan,P.N and Srinivasan, V.A. (2005). Molecular Characterization of Footand-Mouth Disease Virus Type C of Indian Origin. J Clin Microbiol. 43(2): 966-969.

40. Sorensen, J.H., Mackay, K.J., Jensen, C.O \& Donaldson, A.I. (2000). An integrated model to 
predict atmospheric spread of foot and mouth disease virus, Epidemiology and Infection, 124:577590.

41. Donaldson, A.I., Alexandersen, S., Sorensen, H. \& Mikkelsen.(2001). Relative risk of the uncontrollable (air borne) spread of FMD by different species. Vet.Rec. 148:602-604.

42. Rajalakshmi,A, Renugadevi, T.S and Gunasekaran, S (2010). Foot and mouth vaccine on cattle- A spectroscopic analysis. Asian J.Exp. biol.sci.1 (4): 833-839.

43. Kitching, R.P. (2004). Current Global situation of emerging infectious diseases of livestock. FFTC publication database. www.agnet.org/library. php? func

44. Pacheco J.M, Tucker,M, Hartwig,M.E, Ethan,M, Bishop,E, Arzt ,E.J and Rodriguez, E.J.L.(2012). Direct contact transmission of three different footand-mouth disease virus strains in swine demonstrates important strain-specific differences, The Veterinary Journal, www. sciencedirect.com/ science/ article/ pii/S10900 23312000159.

45. Rashtibaf, M., Sharifi, K Zibaee, S. Dehghani H. (2012). A Survey on the Frequency of Foot-andMouth Disease Virus Carriers in Cattle in North-East of Iran by RT-PCR: Implications for Revising Disease Control Strategy. Transboundary and Emerging Diseases. 4.1.2012. DOI: 10.1111/j.1865-1682. 2011. 01299.x.

46. Bao, H.F, Sun, P, Zhou, Q, Hu,J, Bai, X.W, Fu, Y.F, Lu, Z.J and Liu, Z.X (2011). The infectivity and pathogenicity of a foot and mouth disease virus persistent infection strain from oesophargealpharyngeal fluid of Chinese cattle in 2010. Virology Journal. 8:536

47. Calvo,T.R, Segundo,F.D.S, Ramos,M.S and Sevilla.N. (2011). A replication analysis of foot-andmouth disease virus in swine lymphoid tissue might indicate a putative carrier stage in pigs. Veterinary Research, 42:22 doi: 10.1186/1297-9716-42-22.

48. Madhanmohan, M, Nagendrakumar, S.B, Kumar, R., Anilkumar, J, Manikumar, K, Yuvaraj, S and Srinivasan, V.A (2011). Clinical protection, subclinical infection and persistence following vaccination with extinction payloads of $\mathrm{O}_{1}$ Manisa foot-and-mouth disease monovalent vaccine and challenge in goats and comparison with sheep. Research in Veterinary Science www. sciencedirect.com/ science/article/pii/S0034528811004309.

49. Juleff, N, Windsor, M, Reid, E, Seago,J, Monaghan,Z.Z.P, Morrison,I.W, Charleston,B (2008). Foot-and-Mouth Disease Virus Persists in the Light Zone of Germinal Centres. 3(10): e3434. doi:10.1371/journal.pone. 0003434 .

50. Salt, J.S. (1993). The carrier state in foot and mouth disease- an immunological review, British Veterinary Journal, 149(3):207-223.

51. Shanker, H., Sinha, D.K and Singh, B (2004). Epidemiological status on mortality in cattle at organized farm. In Compendium of Abstract of National Symposium on "Latest Approaches and Biotechnological tools for Health Management of Farm and Companion Animals" and XXII Annual Convention of Indian society for Veterinary Medicine, held at IVRI, Izatnagar, during 11-13 February 2004.

52. Oo,K.N (2010). Epidemiological study to support the establishment of a progressive zoning approach for the control of Foot and Mouth Disease in Myanmar. $\mathrm{PhD}$ thesis, Murdoch University. researchrepository. murdoch.edu.au/2974.

53. Domingo, E., Baranowski, E., Escarmis, S. et al. (2002). Foot and mouth disease virus. Comp Immunol Microbiol Infect Dis, 25(5-6):297-308.

54. Barnett P, Garland A.J, Kitching, R.P, et al. (2002) Aspects of emergency vaccination against foot-andmouth disease. Comp Immunol Microbiol Infect Dis 25(5-6):345-64.

55. Tomassen F.H, de Koeijer A, Mourits M.C et al. (2002). A decision tree to optimise control measures during the early stage of FMD epidemic. Prev. Vet. Med. 54 (4):301-324.

56. ahd.kerala.gov.in/index.php/adcp

57. Gray, L.B \& Shulaw, W.P. (2001). Disinfection in onfarm Bio security procedures, Ohio State University Extension fact sheet, VME-8-2001._ohioline.osu.edu/ vme-fact/0008.html.

58. Brito, B. P, Perez, A. M, Cosentino B, Rodriguez, L. L and König, G. A. (2011). Factors Associated With Within-Herd Transmission of Serotype A Foot-andMouth Disease Virus in Cattle, During the 2001 Outbreak in Argentina: A Protective Effect of Vaccination. Transboundary and Emerging Diseases. 58(5):387-393

59. Frenkel, H.S. (1951). Research on FMD II. The cultivation of the virus on a practical scale in explanations of bovine tongue epithelium. Amer.J. Vet.Res.12:187.

60. Selim.A.M.A, Abouzeid, N.Z, Aggour, A.M and Sobhy, N.M.(2010). Comparative study for immune efficacy of two different adjuvants bivalent FMD vaccines in sheep. Journal of American Science, 6 (10).

61. Golde, W.T., Pacheco, J.M., Duque, H. et al (2005). Vaccination against foot and mouth virus confers complete protection in 4 days: use in emergency outbreak response. Vaccine.23 (50): 5775-5782.

62. Guidelines for International standards for vaccine banks, 2008.

63. Perez, A.M., Ward, M.P. \& Carpenter, T.E.(2004). Control of a foot and mouth disease epidemic in Argentina. Prev. Vet. Med.65 (3-4):217-226.

64. Luis,L.R, MarvinJ.G(2009). Foot and mouth disease virus vaccines, Vaccine, 27:D90-D94.

65. Zhang,.L, Zhang,J, Chen, H.T, Zhou, J.H, Ma, L.N, Ding, Y.Z and Liu, Y.S.(2011). Research in advance for FMD novel vaccines. Virology Journal 8:268. 
66. Yang, N.S., Wang, J.H. \& Lin, K.F. et al. (2005). Comparative studies of the capsid precursor polypeptide P1 and the capsid protein VP1 cDNA vectors for DNA vaccination against FMD virus. $J$. Gene Med.7(6); 708-717.

66. Niborski, V., Li, Y., Brennan, F. et al. (2006).Efficacy of particle-based DNA delivery for vaccination of sheep against FMDV. Vaccine 24(49-50): 72047213.

68. Siva Reddy. K, Rashmi. B. R, Dechamma, H. J, Gopalakrishna. S , Banumathi, Suryanarayana, N. V. V. S, Reddy, G. R. (2012). Cationic Micro Particle (PLG) coated DNA vaccination induces a long term immune response against FMD in Guinea Pigs. The Journal of gene Medicine. DOI: 10.1002/jgm.2622.

69. Fowler.V, Robinson. L, Bankowski. B, Cox. S, Parida S, Lawlor. C, Gibson. D, O'Brien, Ellefsen. (2012). A DNA vaccination regime including protein boost and electroporation protects cattle against footand-mouth disease.Antiviral Research. 94(1): 25-
34.

70. Beignon, A.S., Brown, F. \& Eftenkhari, et al.(2005). A peptide vaccine administered transcutaneously together with cholera toxin elicits potent neutralizing anti FMDV antibody responses, Vet.Immunol. immunopathol.104 (3-4): 273-280.

71. Cubillos, C., dela Torre B.G. \& Jakab, A.et al (2008). Enhanced mucosal immunoglobulin A response and solid protection against foot and mouth disease virus challenge induced by a novel dedrimeric peptide. $J$. Virol.82 (14):7223-7230.

72. Pacheco, J.M., Brum, M.C., Moraes, M.P.,Golde, W.T. \& Grubman, M.J. (2005). Rapid protection of cattle from direct challenge with FMDV by a single inoculation with an adenovirus -vectored FMD subunit vaccine. Virology, 337(2):205-209.

73. Grubman, M.J., Moraes, M.P., Schutta, C. et al. (2010). Adenovirus serotype 5-vectored foot-andmouth disease subunit vaccines: the first decade. Future Virol. 5(1): 51-64. 